\title{
Nutritional and Phytochemical Composition of Homemade Chocolates
}

\author{
S. Thilagavathi ${ }^{1 *}$ and Dorothy Jaganathan ${ }^{2}$ \\ ${ }^{1 *}$ Asst professor, Department of Food Science, Periyar University, Salem - 636011, Tamil Nadu, India; \\ thilakachandru@gmail.com, thilagafsn@periyaruniversity.ac.in \\ 2Professor, Department of Food Service Management and Dietetics, Avinashilingam Deemed University, \\ Coimbatore - 641043, Tamil Nadu, India
}

\begin{abstract}
Cocoa has polyphenolic compounds, such as procyanidin monomers, that includes catechin and epicatechin. In the present study fatty acid composition and unique phytochemicals in cocoa based homemade chocolate were assessed in the highly accepted developed product and standard product. The nutrients like carbohydrate, fat and calcium content of standard homemade chocolate has shown reduction as the proportion of cocoa liquor increases viz. $50 \%$ (52.2 g, $42.6 \mathrm{~g}, 38.2 \mathrm{mg}) 60 \%$ (16.2 g, $15.9 \mathrm{~g}, 15.4 \mathrm{mg})$ and $70 \%$ (7 g, $5.4 \mathrm{~g}, 4 \mathrm{mg}$ ) respectively. The other nutrients like protein, fiber, iron, potassium and magnesium contents increased as the proportion of cocoa powder/liquor increases than the standard homemade chocolate. Fatty acids like stearic acid, palmitic acid and oleic acids were present in the developed products. The phytochemical, catechin content in Standard Home Made Chocolates (SHMC) was $5.2 \mathrm{mg}$ whereas the (Developed Home Made Chocolate) DHMC had $7.1 \mathrm{mg}$. Hence the developed product is proven to be rich in phytochemicals as well as various essential nutrients and can be recommended in regular diets.
\end{abstract}

Keywords: Homemade Chocolates, Macronutrients in Chocolates

\section{Introduction}

Due to the high concentration of stearic acid and some flavonoid compounds in dark chocolates, it has the capability to reduce the risks of cardiovascular disease ${ }^{1}$.

Chocolate added in a number of raw and processed foods is produced from the seeds of the tropical Theobroma cocoa tree. Chocolate has become one of the most popular food types and flavors in the world. It is a moderate source of iron. A $50 \mathrm{~g}$ bar of plain chocolate provides about $8 \%$ of the Reference Nutrient Intake (RNI) of iron for women and $14 \%$ of the RNI for a $\operatorname{man}^{2}$. Chocolate found to possess different compounds such as saturated fat, polyphenolic compounds. Also it is rich in polyphenols, particularly in flavan-3-ols such as epicatechins, catechins and procyanidins ${ }^{3}$. Cocoa in chocolate contains a large amount of antioxidants (flavonoids) that may keep high blood pressure down and reduce the blood's ability to clot, thus reducing the risk of stroke and heart attacks. Hence it is said that darker chocolate has most concentrated cocoa and might be most beneficial. The quality attributes of homemade chocolate has not been well documented. Therefore, the objective of this study was to evaluate and compare the nutritional and phytochemical quality of homemade chocolates produced in Salem district. 


\section{Materials and Methods}

\subsection{Development of Chocolates}

Standard Homemade Chocolates (SHMC) were developed based on the procedure of Belitz, (2004) $)^{4}$ and the same with slight modifications were used for making DHMC. The steps include roasting, crushing seeds, removing cocoa nibs, grinding seeds, mixing of ingredients, heating and moulding. Homemade chocolates were prepared incorporating varied proportion of cocoa liquor i.e. $50 \%, 60 \%$ and $70 \%$ except standard. They were subjected to nutritional and phytochemical qualities.

\subsection{Nutrient Assay of Homemade Chocolate}

The standard and developed homemade chocolates were tested for their selected macro and micro nutrients and the methods adopted are given in Table 1.

\section{Results and Discussion}

\subsection{Nutrient Composition of the Homemade Chocolate}

Homemade chocolates prepared from varied proportions of cocoa powder varied with nutrients and chemical compositions.

Table 2 depicts the energy and other nutrient content of both the standard and 50\%, 60\% and 70\% cocoa liquor incorporated homemade chocolates which are represented in Figures 1 and 2. The standard homemade chocolate has $246.4 \mathrm{k} \mathrm{cal}$ and developed product has 208.8, 170.4 and $152.8 \mathrm{k} \mathrm{cal}$ for $50 \%, 60 \%$ and $70 \%$ cocoa incorporation respectively. The calorie, fiber and iron content of chocolate is relatively high for the size of the food. However SHMC had higher concentration of carbohydrate than the DHMC's which implies that cocoa was a fair source of carbohydrate. In SHMC, carbohydrate content was

Table 1. Methods adopted for nutrients analysis

\begin{tabular}{|c|c|}
\hline Nutrients & Methods \\
\hline Carbohydrates & Anthrone method \\
\hline Protein & Kjeldahl method ${ }^{*}$ \\
\hline Fat & Soxhlet method $^{*}$ \\
\hline Potassium & Titration method $^{* *}$ \\
\hline Magnesium & Colorimetric method ${ }^{* *}$ \\
\hline Iron & Wongs method \\
\hline Calcium & Titration method \\
\hline Fibre & AOAC method ${ }^{*}$ \\
\hline
\end{tabular}

Source $\frac{5 \text { and } 6}{}$ 
Table 2. Nutrient composition of the Standard Homemade Chocolateand Developed Homemade Chocolate

\begin{tabular}{|c|c|c|c|c|c|}
\hline \multirow{2}{*}{ S. No } & \multirow{2}{*}{ Parameters } & \multirow{2}{*}{ *SHMC } & \multicolumn{3}{|c|}{${ }^{*} \mathrm{DHMC}$} \\
\hline & & & $50 \%$ & $60 \%$ & $70 \%$ \\
\hline 0 & Energy (k cal) & 246.4 & 208.8 & 170.4 & 152.8 \\
\hline 1 & Carbohydrate (g) & 61.6 & 52.2 & 42.6 & 38.2 \\
\hline 2 & Protein (g) & 12.8 & 13.6 & 13.9 & 14.1 \\
\hline 3 & Fat (g) & 28 & 16.2 & 15.9 & 15.4 \\
\hline 4 & Fibre (g) & 1.5 & 1 & 2.5 & 3 \\
\hline 5 & Iron (mg) & 1.35 & 1.43 & 1.50 & 1.55 \\
\hline 6 & Calcium (mg) & 8.5 & 7 & 5.4 & 4 \\
\hline 7 & Potassium (mg) & 140 & 137 & 141 & 146 \\
\hline 8 & Magnesium (mg) & 43 & 39 & 42 & 46 \\
\hline
\end{tabular}

${ }^{\star}$ SHMC-Standard Home Made Chocolate ${ }^{*}$ DHMC- Developed Home Made Chocolate

$61.6 \mathrm{~g}$ whereas the DHMC with $50 \%, 60 \%$ and $70 \%$ cocoa incorporated chocolates has $52.2 \mathrm{~g}, 42.6 \mathrm{~g}$ and $38.2 \mathrm{~g}$ of carbohydrates respectively.

The protein content of the SHMC was about $12.8 \mathrm{~g}$ and the DHMC of $50 \%, 60 \%$ and $70 \%$ incorporation of cocoa liquor were about $13.6 \mathrm{~g}, 13.9 \mathrm{~g}$ and $14.1 \mathrm{~g}$ respectively, which was higher than the standard. Kinsella $(1970)^{z}$ reported that the protein content of the chocolate samples depend on the initial protein content of different milk sources that influences the nutritional qualities of chocolate. Additionally, protein and fat in milk improves the textural qualities and properties and characterization of cocoa solids.

The amount of fat present in Standard Home Made Chocolate was higher ( $28 \mathrm{~g}$ ) than DHMC. Cocoa beans contain approximately $50 \%$ fat. Evidence have been pro- vided that cocoa administered to rats decreased visceral adipose tissue, thus changing the expression of genes which are involved in the generation of enzymes and molecules for the occurrence of fatty acid synthesis and thermogenesis in liver and white adipose tissue ${ }^{8}$.

With regard to fibre content, DHMC with 70\% incorporation had high fiber content of $3 \mathrm{~g}$. Studies revealed that $100 \mathrm{~g}$ of homemade chocolate contains $3.14 \mathrm{~g}$ of fiber ${ }^{2}$. The amount of iron present in Standard Home Made Chocolate is relatively lower than Developed Home Made Chocolate. The calcium content of standard Home Made Chocolate was $8.5 \mathrm{mg}$ which was greater when compared to $50 \%, 60 \%$ and $70 \%$ of Cocoa liquor incorporated developed Home Made Chocolate bar and their calcium content were found to be $7 \mathrm{mg}, 5.4 \mathrm{mg}$ and $4 \mathrm{mg}$ respectively. 


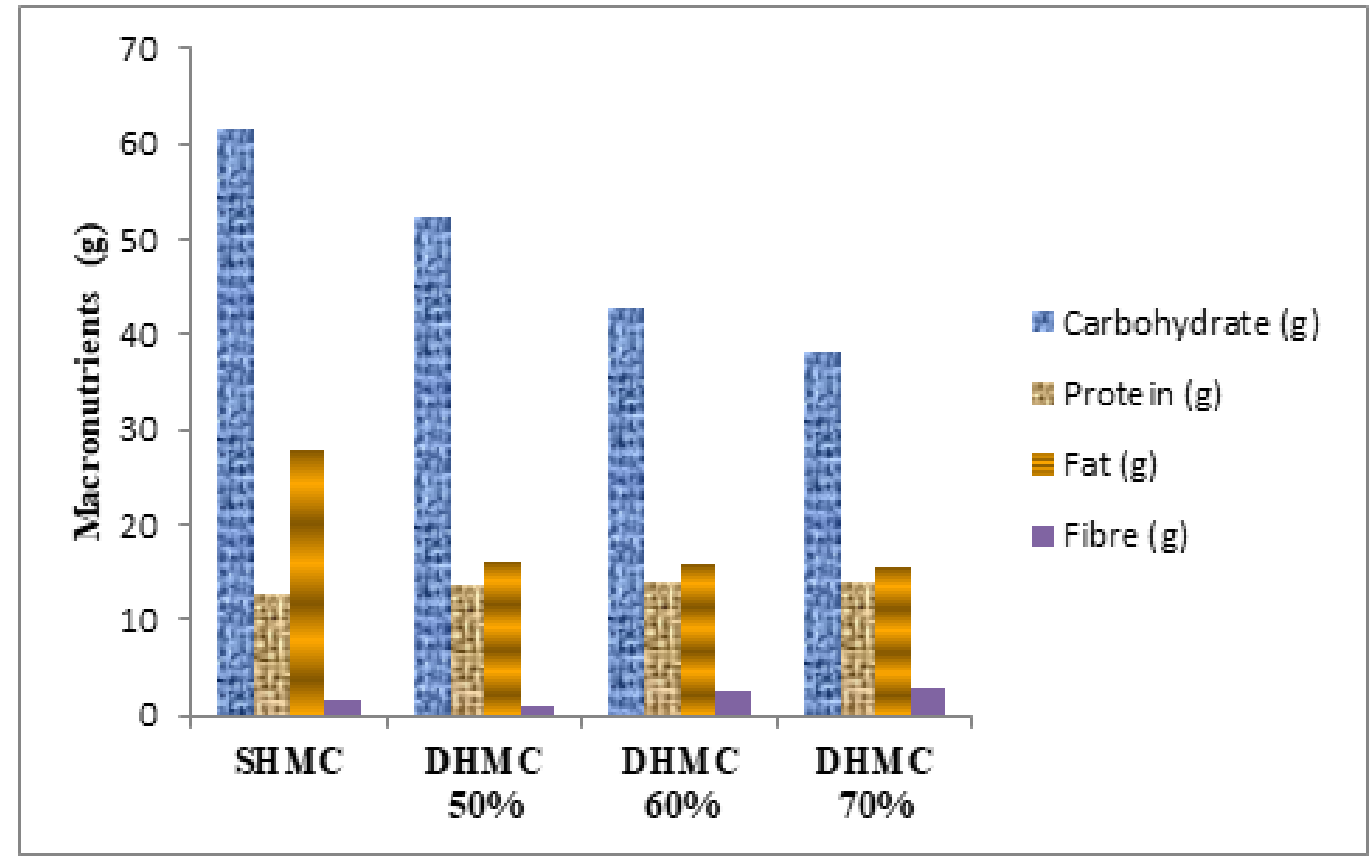

Figure 1. Macronutrient content of the Home Made Chocolate.

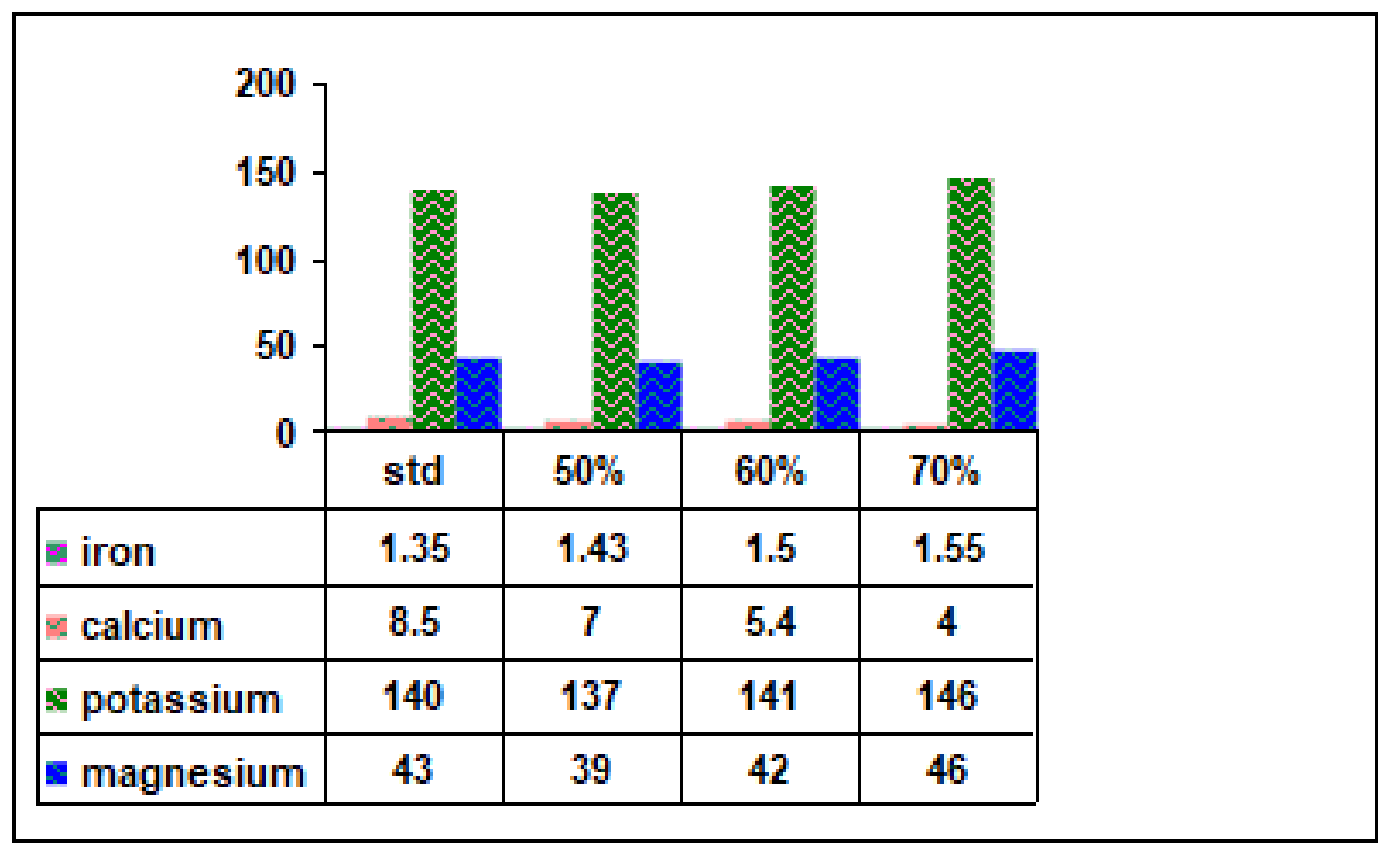

Figure 2. Micronutrient content of the Home Made Chocolate.

Potassium constituted in standard Home Made Chocolate bar was about $140 \mathrm{mg}$ however Developed Home Made Chocolate had $137 \mathrm{mg}, 141 \mathrm{mg}$ and $146 \mathrm{mg}$ for 50\%, $60 \%$ and $70 \%$ incorporation respectively. Among these $70 \%$ has greatest value compared to others. Magnesium content of Standard Home Made Chocolate bar was $43 \mathrm{mg}$, while $50 \%, 60 \%$ and $70 \%$ cocoa liquor incorporated DHMC bars had $39 \mathrm{mg}, 42 \mathrm{mg}$ and $46 \mathrm{mg}$ of magnesium content respec- 
tively. Sharma, (1998) analyzed the amount of potassium and magnesium present in $100 \mathrm{~g}$ of Home Made Chocolate bar found to be $153 \mathrm{mg}$ and $170 \mathrm{mg}$ respectively.

\subsection{Fatty Acid Composition of Homemade Chocolate Bar}

Cocoa butter is unique among natural fats. Its constituent fatty acids are principally the medium-chain saturated fatty acids and the mono unsaturated oleic acid. So it exhibits a remarkable stability against oxidative rancidity. Depending upon the molecule in the fat, they have the tendency to withstand the temperature and remain solid. However it melts below the body temperature.
The Table 3 shows the fatty acids present in Homemade Chocolates. The concentrations of essential fatty acids were found higher in DHMC than the SHMC. According to Ding, (2006) ${ }^{1}$, "In dark chocolates, the fatty acid from added cocoa butter seem to be around $33 \%$ of oleic acid (cis-18:1 mono unsaturated), 25\% palmitic acid (16:0 saturated), and $33 \%$ of stearic acid".

\subsection{Phytochemical-Catechin Content of Homemade Chocolate Bar}

Cocoa beans contain polyphenols with antioxidant properties such as catechins, epicatechins and procyanidins. The antioxidant flavonoids are found in the non fat portions of

Table 3. Percentage of fatty acid composition in SHMC and DHMC

\begin{tabular}{|c|c|c|c|}
\hline S.No & Name of the Component & SHMC & DHMC \\
\hline 1. & Dodecanoic acid (Lauric acid) & 1.50 & 34.9 \\
\hline 2. & Tetradecanoic acid (myristic acid) & 0.45 & 10.6 \\
\hline 3. & n-Hexadecanoic acid (Palmitic acid) & 1.73 & 1.80 \\
\hline 4. & Oleic acid & 2.07 & 2.59 \\
\hline 5. & Octadecanoic acid (Stearic acid) & 0.95 & 1.16 \\
\hline 6. & $1,2-$ Benzenedicarbolic acid (Phthalic acid) & 92.9 & 32.7 \\
\hline 7. & Benzene 1,3,5 trimethyl & 0.09 & - \\
\hline 8. & Butyl octyl ester (Oxiraneoctanoic acid) & 0.28 & - \\
\hline 9. & Octanoic acid (Caprylic acid) & - & 0.19 \\
\hline 10. & Triacetin & - & 0.88 \\
\hline
\end{tabular}

Table 4. Catechin content of SHMC and DHMC

\begin{tabular}{|c|c|}
\hline Foods & Catechin content $\mathbf{~ m g} / \mathbf{g}$ \\
\hline SHMC & 5.2 \\
\hline DHMC & 7.1 \\
\hline
\end{tabular}

SHMC-Standard Home Made Chocolate: DHMC- Developed Home Made Chocolate 


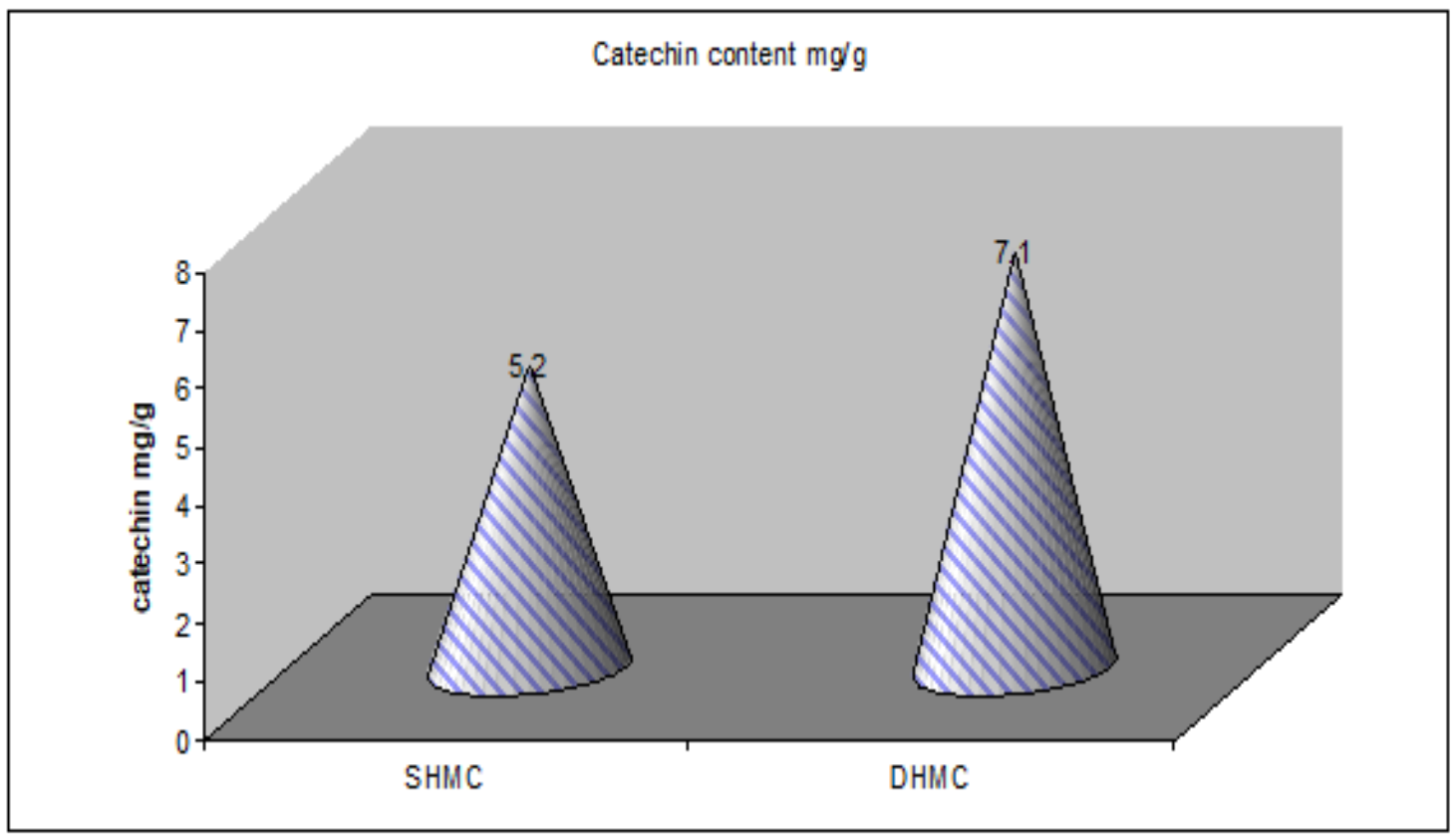

Figure 3. Catechin contents in SHMC and DHMC.

the cocoa bean. The phytochemical-catechin content of the standard and developed Homemade Chocolate bar is given in Table 3 and in Figure 3.

SHMC-Standard Home Made Chocolate: DHMCDeveloped Home Made Chocolate

The Table 4 shows that "SHMC contains $5.2 \mathrm{mg}$ of catechin and the DHMC contains $7.1 \mathrm{mg}$. of catechin clonal variation, growing location, seasonal, light variation and altitude determines the catechin content of the product"10. "The type of microbial colonization and length of fermentation phase will also likely to affect flavanol content and breakdown. Indeed significant variations in the flavanol content of cocoa is noted among different batches and growing areas" $" \underline{11}$. Changes in the flavonoid biochemistry would be expected during the roasting process. Catechin antioxidants are thermally labile to some degree as noted in some studies of thermal stability in tea" $\underline{12}$. "Naturally, the concentration of all of these components can vary considerably depending on the origin and processing of the cocoa"13. Antioxidant flavanols are significantly reduced during the dutching process, neutralization of acetic acid with base which is undesirable for maintaining the flavanol activity in chocolate products" $\underline{14}$.

\section{Conclusion}

The Developed Homemade Chocolate has low calorie, low fat and high catechin content. However, chocolate which is always referred as a pleasure food has been proved from the present study as a nutritious and healthy food for inclusion in regular diets.

\section{Reference}

1. Ding EL, Hutfless SM, Ding X, Girotra S. Chocolate and prevention of cardiovascular disease: A systematic review. Nutrition and Metabolism. 2006; 3:2. doi: 10.1186/17431743-7075-3-2

2. Beckett ST. Industrial chocolate manufacture and use. 2 nd ed. Chapman and Hall, London. 1994. p. 140.

3. Mursu J, Voutilainen S, Nurmi T, Rissanen TH, Virtanen JK, Kaikkonen J, Nyyssonen K, Salonen JT. Dark Chocolate consumption increases HDL cholesterol concentration and chocolate fatty acids may inhibit lipid peroxidation in healthy humans. Free Radical Biology and Medicine. 2004; 37(9):1351-9.

4. Belitz HD. Tea, coffee, cocoa. Food chemistry, 3rd ed. Springer Publication; 2004. p. 960. 
5. Sadasivam S, Manickam A. Biochemical Methods New Age International (P) Ltd. Publishers. 200. p. 30, 34, 184 and 187.

6. Ranganna S. Fruit concentrates and beverages. Analysis of fruit and vegetable products. Tata McGraw Hill Publishing Company Ltd; 2004. p. 872-80.

7. Kinsella JE. Nutritional difference between Dark Chocolate and White Chocolate. Manufacturing Confectionary. 1970; 50:455-7.

8. Matsui N, Itor R, Nishimura E, Yoshikawa M, Kato M, Kamai M. Ingested cocoa can prevent high fat diet induced obesity by regulating the expression of genes for fatty acid metabolism. Nutrition. 2005; 21(5):594-601. 10.1016/j.nut.2004.10.008 (PubMed) (Cross Ref)

9. http://www.caloriecontentoffoods.com/calorie-content-ofchocolate/
10. Chyu KY. Differential effects of green tea derived catechin on developing versus established atherosclerosis in apolipoprotein. Circulation. 2004; 109(25):2448-53.

11. Cushnie, Lamb AJ. Antimicrobial activity of flavonoids. International Journal of Antimicrobial Agents. 2005; 26(5):343-56.

12. Wang R, Zhou W. Kinetic study of the thermal stability of tea catechins in aquenus systems using a microwave reactor. Journal of Agriculture and Food Chemistry. 2006; 54:592432.

13. Aron PM, Kennedy JA. Flavan-3-ols: nature, occurrence and biological activity. Molecular Nutrients, Food Research. 2008; 52:79-104.

14. Stuart DA, Smith NL. Antioxidant activity and polyphenol and procyanidin contents of selected commercially available cocoa containing and chocolate products in the United States. Agricultural Food Chemistry. 2006; 54:4062-8. 